\title{
КОМПОНЕНТНІ МАГНІТНІ Й ЕЛЕКТРИЧНІ ДАВАЧІ ДЛЯ ДІАГНОСТИКИ СТОХАСТИЧНИХ ЕЛЕКТРОМАГНІТНИХ ПОЛІВ
}

\author{
Віталій Нічога ${ }^{1}$, проф., д. т. н., пров. н.с., Людмила Дікмарова ${ }^{1}$, доцент, д. т. н., \\ ст. н.С., Петро Дуб ${ }^{1}$, пров. інж., Здзіслав Качмарек², проф., д. т. н.
}

\author{
Фізико-механічний інститут Національної академії наук України; \\ вул. Наукова, 5, 79601, Львів, Україна; nich@ah.ipm.Iviv.ua \\ 2 Технологічний університет, алея Тисячоліття Польщі, 7, \\ 25-314, Кельце, Польща; etmzk@eden.tu.kielce.pl
}

Анотація: Розглянуто систему давачів апаратури, щзо застосовується для визначення параметрів стохастичних електромагнітних полів. Система призначена для підводного електромагнітного зондування на морському шельфі. Описані нові високочутливі індукиійні давачі, розроблені для иих иілей. Запропонована нова методика визначення орієнтації давачів на морському дні.

Ключові слова: електромагнітне поле, індукційний давач, система давачів, орієнтація, морське зондування

\section{1. ВСТУП}

Інформативні сигнали при електромагнітних зондуваннях як у наземних, так і в морських умовах при пошукових роботах методами становленням поля в ближній зоні в загальному носять стохастичний характер, якщо розглядати процес, викликаний у середовищі одиночним зондуючим імпульсом. Тому необхідно 3 допомогою спеціальних засобів проводити оцінку спектрального складу часових характеристик і просторового розподілу стохастичних електромагнітних полів.

Для аналізу цих електромагнітних полів необхідні відповідні системи давачів. У статті розглядається складна сенсорна система давачів для вимірювання складових поля при підводних морських електромагнітних зондуваннях. Така система дозволяє вимірювати складові згасаючого електромагнітного поля $E$ i $H$, які виникають у морському шельфі за рахунок імпульсного збудження кабелю, розташованого на дні моря. Особливістю цієї сенсорної системи $\epsilon$ те, що в кожній $з$ точок спостереження, які розташовані вздовж і поперек збуджуючого кабелю, потрібно вимірювати три магнітні та дві електричні складові поля [1-3].

\section{2. ДАВАЧІ ДЛЯ МОРСЬКОГО ЕЛЕКТ РОМАГНІТ НОГО ЗОНДУВАННЯ}

Практично при морських зондуваннях зараз використ овують одновиткові індукційні давачі великого діаметру (до 1000 м). Давачі такого розміру в принципі не можуть бути застосовані для вимірювання трьох компонент магнітного поля. А це у свою чергу призводить до втрати цінної інформації, оскільки горизонтальні складові поля можуть давати суттєві додаткові дані про геофізичний розріз морського дна, особливо при горизонтально неоднорідних середовищах. Крім того, неможливо перейти до площинних досліджень, при яких необхідно встановлювати і легко пересувати значну кількість давачів. Вище вказане дозволяє зробити висновок, що перспективи застосування електромагнітного зондування для вивчення морського шельфу перш за все залежать від того, чи вдасться замінити громіздкий індукційний давач рамочного типу зручнішим малогабаритним компонентним давачем магнітного поля [1-4].

Така заміна можлива або шляхом суттєвого збільшення кількості витків, або застосуванням додаткового попереднього підсилювача при відносно невеликій кількості витків. Аналіз показує, що останній варіант кращий.

При розробці таких давачів виникають дві основні проблеми: забезпечення необхідних амплітудно-частотної (АЧХ) та фазочастотної (ФЧХ) характеристик і досягнення низького порогу чутливості. Перше потрібне для отримання корисного сигналу на виході давача 3 мінімальними спотвореннями, друге - для того, щоб на пізніх стадіях досліджуваного процесу сигнал не губився на фоні власних шумів давача. 
В описуваній системі давачів використовуються давачі 3 лінійними амплітудночастотними характеристиками, які традиційно застосовуються в геофізиці.

В основі мобільної сенсорної системи для вимірювання складових магнітного і електричного полів лежать локальний активний низькопороговий індукційний давач (квадратна або кругла рамка 3 розмірами $1,5 г 1,5$ м), який утворює трикомпонентний магнітоприймач, $\mathrm{i}$ коротка електрична антена 3 довжиною $l J 20 \mathrm{M}$, яка утворює двокомпонентний приймач електричного поля [5].

Обмотки всіх трьох давачів магнітного поля виконані у вигляді десятьох витків багатожильного кабелю, намотаних на спеціальний круглий каркас 3 діаметром 1.5 м. Кабель має 108 жил 3 поперечним перерізом 0.5 мм². Жили з'єднані послідовно спеціальним зварюванням. Індуктивність давача 3.5 Гн, активний опір - 180 Ом, маса однієї компоненти - 50 кг, ефективна фізична площа однієї компоненти давача $2000 \mathrm{M}^{2}$. Кожний давач має окремий малошумний підсилювач (МШП) $з$ коефіцієнтом підсилення $\sim 50$.

\section{3. СИСТЕМА ОРІЄНТАЦІЇ ДАВАЧІВ}

При компонентних вимірюваннях будь-яких полів (зокрема, електромагнітних) потрібно знати проекції вимірюваного вектора в певній системі координат, яку називатимемо базовою (БСК). Якщо при цьому система сенсорів знаходиться в легко доступному середовищі, наприклад, на поверхні Землі, орієнтація осей чутливості сенсорів уздовж осей БСК не становить труднощів. Але при роботі на дні доводиться примусово орієнтувати давачі. У таких випадках необхідно застосовувати гіростабілізаційні системи та навігаційне устаткування, що може призвести до ускладнення апаратури і появи додаткових електромагнітних завад. Тому у ряді випадків доцільно 3 метою підвищення точності зорієнтувати сенсори інакше, коли їхні осі утворюватимуть власну систему координат (ВСК), яка не збігається з БСК. Але на поверхні Землі можна легко визначити орієнтацію ВСК відносно БСК і здійснити перерахунок виміряних складових вектора поля з однієї системи координат в іншу. Якщо ж система сенсорів знаходиться в середовищі, доступ до якого суттєво ускладнений, то розв'язання проблеми орієнтації стає значно важчим. Така ситуація виникає при електромагнітному зондуванні морського шельфу, коли сенсори розташовують на дні моря, де вони утворюють ВСК, а БСК зорієнтована вздовж кабелю, що є джерелом зондуючого сигналу. Здебільшого одна вісь БСК перпендикулярна поверхні, одна $з$ горизонтальних осей спрямована вздовж кабелю, а друга - перпендикулярно йому. Оскільки магнітне поле у даному випадку неоднорідне i вимірювати його на поверхні води неможливо, то потрібно виміряні на дні компоненти поля перерахувати у БСК. Для цього розроблена система визначення орієнтації довільно розташованих на дні первинних вимірювальних перетворювачів відносно БСК. Таке визначення можливе при вимірюванні просторових компонент двох неколінеарних векторів у обох системах координат. Розроблена система визначення орієнтації базується на основі вимірювань магнітного і гравітаційного поля Землі на поверхні і на дні. При цьому враховано, що ці поля на поверхні практично ідентичні полям на дні. Розроблено також алгоритм перерахунку компонент вектора магнітного поля в БСК [3].

Будь-який вектор $\vec{A}$, виміряний у ВСК, має наступні компоненти в БСК:

$$
A_{X}=A_{X^{\prime}} \cos \left(i i^{\prime}\right)+A_{Y^{\prime}} \cos \left(i j^{\prime}\right)+A_{Z^{\prime}} \cos \left(i k^{\prime}\right),
$$

$$
A_{Y}=A_{X^{\prime}} \cos \left(j i^{\prime}\right)+A_{Y^{\prime}} \cos \left(j j^{\prime}\right)+A_{Z^{\prime}} \cos \left(j k^{\prime}\right),
$$

$A_{Z}=A_{X^{\prime}} \cos \left(k i^{\prime}\right)+A_{Y^{\prime}} \cos \left(k j^{\prime}\right)+A_{Z^{\prime}} \cos \left(k k^{\prime}\right) ;$

де $A_{X}, A_{Y}, A_{Z}$ - координати в БСК, $A_{X^{\prime}}$, $A_{Y^{\prime}}, A_{Z^{\prime}}-$ координати в БСК, коефіцієнти при $A_{X^{\prime}}, A_{Y^{\prime}}, A_{Z^{\prime}}$ - косинуси кутів між ортами двох систем координат.

Ці коефіцієнти можна визначити, знаючи компоненти двох неколінеарних векторів ( $\vec{C}$ i $\vec{D}$ ), виміряних у БСК і ВСК. Використовуючи інваріантність модулів векторів і кута між ними до системи координат, можна отримати:

$$
\begin{aligned}
& \cos \left(i i^{\prime}\right)=\left[|C|^{2} D_{X} D_{X^{\prime}}+|D|^{2} C_{X} C_{X^{\prime}}-\left(C_{X} D_{X^{\prime}}+C_{X^{\prime}} D_{X}\right) \times\right. \\
& \left.\times \sum C D+\left(C_{Z^{\prime}} D_{Y^{\prime}}-C_{Y^{\prime}} D_{Z^{\prime}}\right)\left(C_{Z} D_{Y}-C_{Y} D_{Z}\right)\right] \times \\
& \times\left[|C|^{2}|D|^{2}-\left(\sum C D\right)^{2}\right]^{-1},
\end{aligned}
$$




$$
\begin{aligned}
& \cos \left(i j^{\prime}\right)=\left[|C|^{2} D_{X} D_{Y^{\prime}}+|D|^{2} C_{X} C_{Y^{\prime}}-\left(C_{X} D_{Y^{\prime}}+C_{Y^{\prime}} D_{X}\right) \times\right. \\
& \left.\sum C D+\left(C_{X^{\prime}} D_{Z^{\prime}}-C_{Z^{\prime}} D_{X^{\prime}}\right)\left(C_{Z} D_{Y}-C_{Y} D_{Z}\right)\right] \times \\
& \cos \left(i k^{\prime}\right)=\left[|C|^{2} D_{X} D_{Z^{\prime}}+|D|^{2} C_{X} C_{Z^{\prime}}-\left(C_{X} D_{Z^{\prime}}+C_{Z^{\prime}} D_{X}\right) \times\right. \\
& \left.\times \sum C D+\left(C_{Y^{\prime}} D_{X^{\prime}}-C_{X^{\prime}} D_{Y^{\prime}}\right)\left(C_{Z} D_{Y}-C_{Y} D_{Z}\right)\right] \times \\
& \times\left[|C|^{2}|D|^{2}-\left(\sum C D\right)^{2}\right]^{-1},
\end{aligned}
$$

$$
\cos \left(j i^{\prime}\right)=\left[|C|^{2} D_{Y} D_{X^{\prime}}+|D|^{2} C_{Y} C_{X^{\prime}}-\left(C_{Y} D_{X^{\prime}}+C_{X^{\prime}} D_{Y}\right) \times\right.
$$$$
\left.\times \sum C D+\left(C_{Z^{\prime}} D_{Y^{\prime}}-C_{Y^{\prime}} D_{Z^{\prime}}\right)\left(C_{X} D_{Z}-C_{Z} D_{X}\right)\right] \times
$$$$
\times\left[|C|^{2}|D|^{2}-\left(\sum C D\right)^{2}\right]^{-1},
$$

$\cos \left(j j^{\prime}\right)=\left[|C|^{2} D_{Y} D_{Y^{\prime}}+|D|^{2} C_{Y} C_{Y^{\prime}}-\left(C_{Y} D_{Y^{\prime}}+C_{Y^{\prime}} D_{Y}\right) \times\right.$

$$
\begin{aligned}
& \left.\sum C D+\left(C_{X^{\prime}} D_{Z^{\prime}}-C_{Z^{\prime}} D_{X^{\prime}}\right)\left(C_{X} D_{Z}-C_{Z} D_{X}\right)\right] \times \\
& \times\left[|C|^{2}|D|^{2}-\left(\sum C D\right)^{2}\right]^{-1},
\end{aligned}
$$

$$
\begin{aligned}
& \cos \left(j k^{\prime}\right)=\left[|C|^{2} D_{Y} D_{Z^{\prime}}+|D|^{2} C_{Y} C_{Z^{\prime}}-\left(C_{Y} D_{Z^{\prime}}+C_{Z^{\prime}} D_{Y}\right) \times\right. \\
& \left.\times \sum C D+\left(C_{Y^{\prime}} D_{X^{\prime}}-C_{X^{\prime}} D_{Y^{\prime}}\right)\left(C_{X} D_{Z}-C_{Z} D_{X}\right)\right] \times
\end{aligned}
$$

$\cos \left(k i^{\prime}\right)=\left[|C|^{2} D_{Z} D_{X^{\prime}}+|D|^{2} C_{Z} C_{X^{\prime}}-\left(C_{Z} D_{X^{\prime}}+C_{X^{\prime}} D_{Z}\right) \times\right.$

$$
\begin{aligned}
\times & \left.\sum C D+\left(C_{Z^{\prime}} D_{Y^{\prime}}-C_{Y^{\prime}} D_{Z^{\prime}}\right)\left(C_{Y} D_{X}-C_{X} D_{Y}\right)\right] \times \\
& \times\left[|C|^{2}|D|^{2}-\left(\sum C D\right)^{2}\right]^{-1},
\end{aligned}
$$

$$
\cos \left(k j^{\prime}\right)=\left[|C|^{2} D_{Z} D_{Y^{\prime}}+|D|^{2} C_{Z} C_{Y^{\prime}}-\left(C_{Z} D_{Y^{\prime}}+C_{Y^{\prime}} D_{Z}\right) \times\right.
$$$$
\left.\sum C D+\left(C_{X^{\prime}} D_{Z^{\prime}}-C_{Z^{\prime}} D_{X^{\prime}}\right)\left(C_{Y} D_{X}-C_{X} D_{Y}\right)\right] \times,
$$

$$
\cos \left(k k^{\prime}\right)=\left[|C|^{2} D_{Z} D_{Z^{\prime}}+|D|^{2} C_{Z} C_{Z^{\prime}}-\left(C_{Z} D_{Z^{\prime}}+C_{Z^{\prime}} D_{Z}\right) \times\right.
$$$$
\left.\times \sum C D+\left(C_{Y^{\prime}} D_{X^{\prime}}-C_{X^{\prime}} D_{Y^{\prime}}\right)\left(C_{Y} D_{X}-C_{X} D_{Y}\right)\right] \times
$$

$$
\times\left[|C|^{2}|D|^{2}-\left(\sum C D\right)^{2}\right]^{-1} ;
$$

де $C_{X}, C_{Y}, C_{Z}, D_{X}, D_{Y}, D_{Z}$ - компоненти у БСК; $C_{X^{\prime}}, C_{Y^{\prime}}, C_{Z^{\prime}}, D_{X^{\prime}}, D_{Y^{\prime}}, D_{Z^{\prime}}$ - компоненти у ВСК;

$\sum C D=C_{X} D_{X}+C_{Y} D_{Y}+C_{Z} D_{Z}=C_{X^{\prime}} D_{X^{\prime}}+$ $+C_{Y^{\prime}} D_{Y^{\prime}}+C_{Z^{\prime}} D_{Z^{\prime}}$.

У нашому випадку БСК утворена віссю X, що збігається з горизонтальною складовою вектора магнітного поля Землі, віссю Z, що збігається з вертикальною складовою цього вектора і вектором земного тяжіння, та віссю $\mathrm{Y}$, яка утворює разом з осями X і Y праву систему векторів (Рис.1).

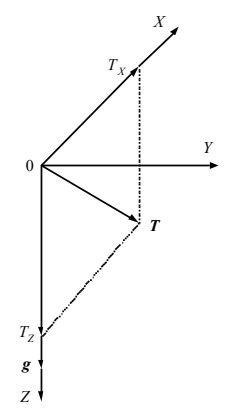

Рис. 1. Базова система координат.

У ВСК, коли підводні давачі розташовані на дні довільно, ці вектори мають наступні компоненти: $T_{X^{\prime}}, T_{Y^{\prime}}, T_{Z^{\prime}}, g_{X^{\prime}}, g_{Y^{\prime}}, g_{Z^{\prime}}$. Ці компоненти можуть бути виміряні ферозондом i акселерометром, після чого можна знайти коефіцієнти перетворення досліджуваного магнітного поля у БСК. Це перетворення можна виразити наступними формулами:

$$
\begin{aligned}
& H_{X}=H_{X^{\prime}} \frac{g_{Z} T_{X^{\prime}}-g_{X^{\prime}} T_{Z}}{g_{Z} T_{X}}+H_{y^{\prime}} \frac{g_{Z} T_{Y^{\prime}}-g_{Y^{\prime}} T_{Z}}{g_{Z} T_{X}}+ \\
& H_{Z^{\prime}} \frac{g_{Z} T_{Z^{\prime}}-g_{Z^{\prime}} T_{Z}}{g_{Z} T_{X}}, \\
& H_{Y}=H_{X^{\prime}} \frac{g_{Y^{\prime}} T_{Z^{\prime}}-g_{Z^{\prime}} T_{Y^{\prime}}}{g_{Z} T_{X}}+H_{Y^{\prime}} \frac{g_{Z^{\prime}} T_{X^{\prime}}-g_{X^{\prime}} T_{Z^{\prime}}}{g_{Z} T_{X}}+ \\
& H_{Z^{\prime}} \frac{g_{X^{\prime}} T_{Y^{\prime}}-g_{Y^{\prime}} T_{X^{\prime}}}{g_{Z} T_{X}} \\
& H_{Z}=H_{X^{\prime}} \frac{g_{X^{\prime}}}{g_{Z}}+H_{Y^{\prime}} \frac{g_{Y^{\prime}}}{g_{Z}}+H_{Z^{\prime}} \frac{g_{Z^{\prime}}}{g_{Z}} ;
\end{aligned}
$$


де $H_{X^{\prime}}, H_{Y^{\prime}}, H_{Z^{\prime}}$ - компоненти досліджуваного поля у ВСК; $H_{X}, H_{Y}, H_{Z}$ - вони ж у БСК.

\section{4. СИСТЕМА ДАВАЧІВ “ГЕОЗОНД”}

Основними параметрами сенсорної системи для вимірювання магнітних полів $€$ чутливість $\mathrm{i}$ поріг чутливості по магнітному полю окремої компоненти [6].

Для компонентного індукційного давача магнітного поля, який використовується у сенсорній системі, його чутливість визначається наступним простим виразом [6]:

$$
G=U_{C} / B=2 \pi f w S K_{\text {вx }} K_{\Pi}, \text { В/Тл, }
$$

де $U_{C}$ - напруга сигналу на виході давача, $f$ - частота сигналу, $S$ - площа поперечного перерізу рамки давача, $w$ - кількість витків рамки давача, $K_{6 x}$ - коефіцієнт передачі ЕРС давача на вхід попереднього підсилювача, $K_{\Pi}$ - коефіцієнт підсилення по напрузі попереднього підсилювача.

Вираз (16) наведений для давача 3 плоскою або частото-незалежною АЧХ. Для давача 3 лінійною АЧХ чутливість нормується по частоті і визначається наступним виразом [6]:

$$
G_{f}=2 \pi w S K_{\theta x} K_{\Pi}, \mathrm{B} /(\text { ТлЧГц). }
$$

Поріг чутливості давача по полю визначається 3 умови рівності одиниці співвідношення сигналшум на виході давача. Якщо спектральна густина шуму на виході давача (з урахуванням шумів попереднього підсилювача) однакова в смузі частот $\Delta f$ і дорівнює $S_{u}$, то поріг чутливості визначатиметься наступним чином [6]:

$$
B_{\text {пор }}=\frac{\sqrt{S_{u}}}{2 \pi f w S K_{\text {вx }} K_{\Pi}}=\frac{\sqrt{S_{u}}}{2 \pi f S_{\text {екв }}}, \text { Тл, }
$$

де $S_{\text {екв }}=S w K_{в x} K_{\Pi}$ - еквівалентна площа давача.

У ряді випадків, особливо на низьких частотах, де згадані умови по $S_{u}$ не виконуються, користуються спектральною густиною порогу чутливості давача на заданій частоті $f$, яка визначається залежністю:

$$
B_{\text {nоp }}=\frac{\sqrt{S_{u \Delta f=1}}}{2 \pi f w S K_{\theta x} K_{\Pi}}=\frac{\sqrt{S_{u \Delta\lrcorner f=1}}}{2 \pi f S_{\text {екв }}}, \text { Тл/ГЦ } \amalg^{1 / 2} .
$$

Аналогічним чином може бути визначена чутливість і спектральна густина порогу чутливості давача електричного поля.

Структурна схема системи давачів “Геозонд" з подана на рис. 2. Тут прийняті наступні позначення: ПП-первинний перетворювач давача, БКК - блок калібровки та компенсації, МШП - малошумний підсилювач, А - атенюатор, АЦП - аналого-цифровий перетворювач, РУСС - радіостанція управління, сигналу та синхронізації, яка розміщена в автономному буї. Ця радіостанція сполучає систему давачів 3 судном, де знаходяться генератор імпульсного поля і комп'ютерноінформаційний комплекс обробки сигналів.

Основні технічні параметри індукційних давачів для системи давачів "Геозонд":

1. Частотний діапазон -0.01 ё2000 Гц.

2. Номінальний коефіцієнт перетворення

$G_{f}-6.3 Ч 10^{5} \mathrm{~B} /($ ТлЧГц).

3. Форма амплітуд-частотної характеристики - лінійна.

4. Коефіцієнт підсилення малошумного підсилювача (МШП) - 50.

5. Еквівалентна площа рамки кожної компоненти давача $S_{\text {екв }}-1410^{5} \mathrm{M}^{2}$.

6. Маса системи давачів - 150 кг.

Пороги чутливості системи давачів “Геозонд” подані в таблиці 1.

Основні характеристики давача електричного поля :

1. Частотний діапазон $-0.01 \div 2000$ Гц.

2. База давача -20 м.

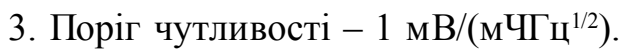

Система давачів "Геозонд" призначена для електромагнітного зондування методами становлення поля шельфу Чорного моря. Метою цих досліджень $€$ виявлення нафто-газових полів.

\section{5. ВИСновки}

1. Створена система давачів "Геозонд" малогабаритними і високочутливими давачами

Таблиця 1. Пороги чутливості по магнітній індукції системи давачів “Геозонд”

\begin{tabular}{|c|c|c|c|c|c|c|}
\hline $\mathbf{f}, \boldsymbol{\Gamma} \mathbf{L}$ & 0.1 & 1 & 10 & 100 & 1000 & 2000 \\
\hline $\begin{array}{c}\mathbf{B}, \\
\mathbf{н Т л} / \mathbf{L}^{\mathbf{1} 2}\end{array}$ & $1.5 \cdot 10^{-2}$ & $1.4 \cdot 10^{-3}$ & $5.4 \cdot 10^{-5}$ & $3 \cdot 10^{-6}$ & $1.5 \cdot 10^{-6}$ & $1.5 \cdot 10^{-6}$ \\
\hline
\end{tabular}




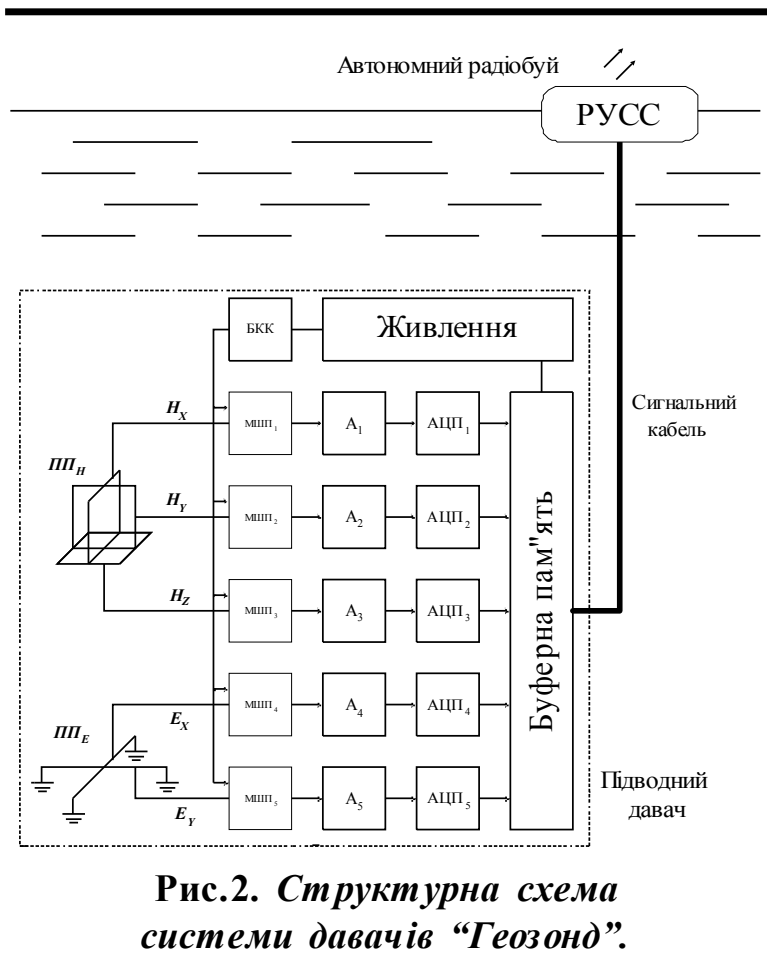

для вимірювань трьох компонент магнітного поля і двох компонент електричного поля на морському шельфі.

2. Розроблена методика визначення орієнтації давачів на дні 3 використанням вимірювань магнітного і гравітаційного полів Землі у базовій і власній системах координат.

\section{6. ЛITЕРАТУРА}

[1] Сапужак Я.С., Білінський А.І., Дещзиия С.А., Лукенюк А.А., Нічога В.О. Апаратурнометодичний комплекс для електромагнітних досліджень нафтогазових покладів // Тези доповідей $і$ повідомлень науково-практичної конференції “Стан, проблеми $і$ перспективи

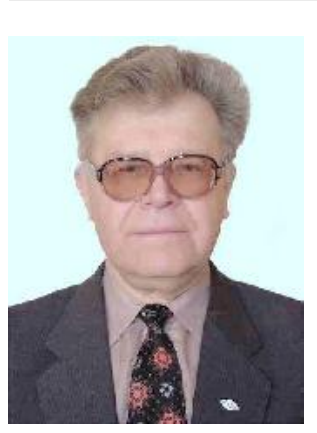

Віталій Нічога народився у Києві у 1938 р. Закінчив радіотехнічний фракультет Національного університету "Львівська політехніка" у 1960 р. Учений ступінь кандидата наук у галузі електричних і радіотехнічних вимірювань здобув у 1966 р. У 1968 p. отримав звання старшого наукового співробітника. У 1996 р. здобув учений ступінь доктора технічних наук у Київському інституті керування ізв'язку. Працює у Фізикомеханічному інституті ім. Г. В. Карпенка Національної академії наук України з 1960 p. науковим співробітником з 1960 р. Зараз займає посаду провідного наукового співробітника відділу відбору та обробки стохастичних сигналів. Одночасно Нічога є профресором розвитку нафтогазового комплексу західного регіону україни” (Львів, 28-30 березня 1995 р.) - Львів - 1995. - С. 137-138.

[2] Сапужак Я.С., Дещчища С.А., Романюк О.И., Лукенюк А.А.. Ничога В.А., Дуб П.Б. Аппаратурно-методический комплекс для электромагнитных исследований шельфовых зон // Международная геофизическая конферениия "Электромагнитные исследования с контролируемыми источниками” (Петродворец, 27-31 мая 1996) - СанктПетербург - 1996 - С.75-76.

[3] Нічога В.О., Дуб П.Б. Датчики для систем електромагнітних досліджень шельфових зон та їхня орієнтація під водою // Тези доповідей Третьої украӥнської конферениї з автоматичного керування (“Автоматика-96”) (Севастополь, 9-14 вересня 1996) - Севастополь - 1996 - Частина III C. 38 .

[4] Ничога В.А. Измерение весьма слабых низкочастотных магнитных полей в геофизических и космических исследованиях // Отбор и передача информации. - Bыn.9. 1993. - C. 70-77.

[5] Ничога В.А. Дуб П.Б. Захаркин А.К. Локальные активные низкопороговые индукционные датчики /ЛАНИД/ и их использование в электроразведочных работах по методу ЗСБ и ЗСМП // Геофизическая annapamypa. - 1999. - Buin. 102. - C. 28-34.

[6] Крупногабаритные геофизические петлев ые индукционные преобразователи и возможности их замены локальными активнымми датчиками / Гнатюк А.С., Дуб П.Б., Ничога В.А., Ясиновый А.С. // Геофизическая annapamypa. - 1994. - Bbın.98. - C.31-38.

кафедри радіоелектронних пристроїв і систем радіотехнічного фракультету Національного університету “Львівська політехніка" та членом редколегії наукового журналу "Радіоелектроніка та телекомунікації”, який видається цим університетом.

Основні наукові інтереси Нічоги: методи й засоби вимірювання магнітних величин, розробка математичних моделей електромагнітних полів, створення на основі використання нових фозичних явищ, технологій та магнітних матеріалів високоефективних мобільних антен та давачів для вимірювання слабких електромагнітних полів, які застосовуються у таких галузях як діагностика та неруйнівний контроль, геофізичні та космічні дослідження, захист інфрормації у телекомунікаційних системах. Нічога - автор понад 190 наукових праць, у тому числі двох монографій; отримав 10 авторських свідоцтв та патентів. 


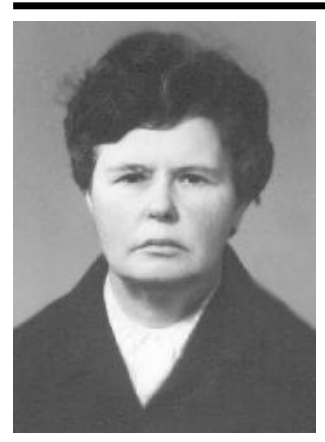

Людмила Дікмарова народилася в м. Узин Київської області у 1927 р. Закінчила Національний університет "Львівська політехніка" у 1950 р. Здобула вчений ступінь кандидата технічних науку галузі електричних вимірювань у 1954 р. У 1959 р. їй присвоєно звання доцента кафедри фізики. У 1989 р. здобула вчений ступінь доктора технічних наук. У 1954-1960 роках викладала електротехніку у Львівському педагогічному інституті. З 1960 р. працюе старшим науковим співробітником у Фізикомеханічному інституті ім. Г. В. Карпенка Національної академії наук України. Основні наукові інтереси Дікмарової пов'язані з дослідженням електромагнітних полів у кусочнонеоднорідних середовищах у таких галузях як вимірювання слабких електромагнітних полів та обстеження підземних трубопроводів. Людмила Дікмарова опублікувала 125 наукових праць, утому числі 4 монографрії.

Петро Дуб народився у Львові у 1954 р. У 1977 p. закінчив факультет автоматики Національного університету “Львівська політехніка". Працює зтого часу на посадах інженера і провідного інженера у Фізикомеханічному інституті ім. Г. В. Карпенка Національної академії наук України.

Його основними науковими інтересами $\epsilon$ вивчення електромагнітних полів і розробка апаратури для їх вимірювання. Автор 75 наукових праць.

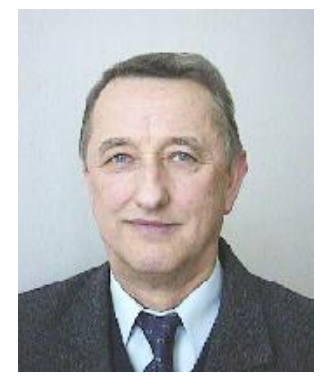

здзіслав Качмарек народився у Польщі в 1940 р. У 1964 р. він закінчив Технологічний університет $y$ Вроилаві, здобувши ступінь магістра в галузі зв'язку та електроніки. З 1964 по 1977 р. працював у Любліні в мідновидобувному науководослідному інституті, де розробляв системи вимірювань та безпровідного підземного зв'язку. У 1977 р. здобув учений ступінь доктора наук угалузі електричної метрології в Технологічному університеті у Врочлаві. 3 того часу працює в Технологічному університеті в Кельце як доцент, а з 1990-як профресор. Займається дослідженням питань відновлення і обробки вимірювальних сигналів, вимірюванням неелектричних величин електричними методами, а також електронними i волконно-оптичними давачами. Член секції вимірювального обладнання метрологічного комітету Польської академії наук. 